the appropriate temperature of $3-5^{\circ}$ C. $\left(37-41^{\circ}\right.$ F.). It has been reported ${ }^{4}$ that machines vending perishable foods in the U.S.A. are required to hold those foods under refrigeration or alternatively above $140^{\circ} \mathrm{F} .\left(60^{\circ} \mathrm{C}\right.$.). In one district perishable foods and sandwiches with perishable fillings are required to be marked with the date of manufacture and permitted only 24 hours' storage in the machine. Perishable foods vended in the U.K. might be marked with the date of manufacture or a statement giving the final date for consumption. Machines should be sited away from the direct rays of the sun or suitable protection provided, ${ }^{5}$ and only heattreatéd milk should be used in vending machines.

It is important that foods intended to be eaten hot should be maintained at temperatures above $145^{\circ} \mathrm{F}$. $\left(62^{\circ} \mathrm{C}\right.$.), as recommended in the Code of Practice. H. L. Hughes ${ }^{4}$ reports that in the U.S.A. a microwave oven may be included in the range of vending machines to allow quick cooking of small articles of food provided by other machines. C. A. Bailey ${ }^{6}$ describes incidents of chemical poisoning from vended fruit juices and recommends that occasional checks should be made for the metallic content of fruit juice vended from machines.

In the interests of public health there would seem to be need for close co-operation between the various sections of the food industry engaged in packaging and automatic vending and the public health authorities. ${ }^{7}$ Moreover, as a precautionary measure firms intending to buy vending machines might be well advised to dismantle and reassemble the apparatus to check that it can be operated and cleaned in an efficient manner.

\section{One Step Nearer?}

According to the Treaty of Rome its provisions were to come into effect not later than 12 years from the signing of it in 1957. The treaty provides for free movement of doctors within the countries of the Common Market. The articles which deal with the matter are mainly article 48 , which covers freedom of movement, and article 57, which refers to directives about mutual recognition of diplomas, certificates, and other qualifications, and the progressive removal of restrictions. To put these articles into effect certain adjustments in the conditions of practice and educational systems of the member countries will be required.

The Permanent Medical Committee of the European Economic Community, which, as previously explained, ${ }^{1}$ was formed in 1956 with representatives from national medical associations of the member States and is a purely advisory body with no executive power, has made recommendations on these matters. These recommendations have been presented to the Commission-the standing administrative body of the European Economic Community-and last month the appropriate working party of the Commission met in Brussels to draft a directive on the subject. The working party, which is composed of civil servants, is also concerned with other professions-such as law, engineering, and architectureand its directive should embody the plans for free movement of these as well as the medical profession. A draft should be presented by the end of the year to the Commission, whence it will go to the Council of the Ministers of the Six next year. It has to be unanimously approved by the Council and the European Parliament in Strasbourg and will then be referred back for ratification in the respective Parliaments of the member States. It could become implemented by January 1969.

The Permanent Medical Committee does not believe that this programme will give enough time. It thinks there is need for a delay of about five years to allow the various problems to be solved satisfactorily. In its view there are two major stumbling-blocks. Firstly, although some agreement has been reached in principle on the medical curricula of the member countries, there is a considerable difference in length and type of training for both graduation and specialization in each of the countries of the Six. Secondly, the social security systems in each country will require some harmonization. The medical administration of each country is closely linked with its social security system, and modifications may not be simple.

Opinion in Brussels is optimistic that Britain's entry to the Six may become a reality in about two years. Since new entrants are required to go through a transition period before full integration with the European Community, doctors here will have the opportunity of observing how matters are working out for their colleagues on the Continent, if the timetable envisaged by the Community's civil servants is fulfilled.

\section{Elusive Popliteal Pulse}

Fortunately in the majority of sites where we wish to determine the existence of an arterial pulse the vessel is near both to the surface and to the underlying bone. Thus the detection of the carotid, subclavian, brachial, radial, femoral, and foot pulses is easy. It is not so with the popliteal pulse. It is often essential to know whether the popliteal pulse is present or absent-for example, to distinguish a block of the lower femoral artery from one of the popliteal artery-yet many students, some of them postgraduate, have been heard to say that they have never felt it.

R. Ger ${ }^{1}$ points out that the lower half of the popliteal artery is nearest to bone and skin as it lies behind the head of the tibia, and that this should be the standard point for palpating it. In fact there are three methods of palpating this artery, and the clinician may have to try them all before being sure, that the pulse is absent. The commonest method is to grasp the upper end of the tibia with both hands-thumbs in front, fingers behind-with the knee slightly flexed. If the fingers are then moved from side to side they slip over the neurovascular bundle, which, once identified, can be fixed between the fingertips and compressed back against the bone. Occasionally it is easier to feel the artery higher up, behind the lower end of the femur, by hyperextending the knee joint with one hand pushing backwards on the patella, and placing the fingers of the other hand between the popliteal fossa and the bed. Both of these methods may be ineffectual in an obese person.

Probably the best and most certain way to feel the popliteal pulse is to have the patient in the prone position. The whole length of the popliteal fossa can then be palpated with the tips of the fingers of both hands. A pulse that cannot be felt in this way is surely absent. As with all clinical techniques, success comes from constant practice and, in the matter of palpating the popliteal pulse, self-discipline. A quick feel behind the knee is of no value. The approach must be slow, deliberate, and painstaking. 